\title{
Policy and contextual considerations for enabling learning support roles in digital environments
}

\author{
Jill Stefaniak ${ }^{1}$ (i)
}

Accepted: 22 October 2020 / Published online: 23 November 2020

(c) Association for Educational Communications and Technology 2020

\begin{abstract}
This paper is in response to Nacu et al.'s (Educ Technol Res Dev 66(4):1029-1049, 2018) guidelines to enable educators to fulfill learner support roles in online education from a contextual perspective and how their heuristic method can be utilized in today's current pandemic. It also explores how learner support roles can be leveraged to balance affordances offered by the learning environment and the learners themselves. Additionally, this paper discusses the implications for addressing social inequities in digital environments and education policy reform.
\end{abstract}

Keywords Learner support · Teacher development · Educational policy · Online instruction

Nacu et al.'s (2018) study, Designing for 21st Century Learning Online: A Heuristic Method to Enable Educator Learning Support Roles, explored the extent that supportive roles upheld by educators can guide learners within a learning management system. The authors expanded upon a framework they had previously developed, the Online Learning Support Roles (OLSR) framework (Nacu et al. 2016), and presented heuristics to help educators embody a more supportive instructor presence in youth-centered online learning environments.

The authors made a strong argument for a heuristic method to support educators' adoption of learning support roles in online environments. Their paper upheld the premise of empathetic design by examining how educators can fulfill several supportive roles, both intermittently and concurrently, to meet their learner's needs. As teachers pivot to delivering online instruction and promote some sense of normalcy to their learners during the pandemic, Nacu et al.'s (2018) heuristics for embracing different supportive roles is of great benefit to both experienced and inexperienced online learning educators.

These unprecedented times have highlighted several social inequities that have been impacted by schools' decisions to make drastic changes to instructional delivery. Examples of inequities impacting students' abilities to shift to digital environments include access to the internet, accessibility, and resources available for students requiring individualized education plans. Other contextual factors influencing students' learning environments include

Jill Stefaniak

Jill.stefaniak@uga.edu

1 University of Georgia, 850 College Station Road, 221 Rivers Crossing, Athens, GA 30602, USA 
their parents'/guardians' ability to support and assist them with learning, having appropriate space to learn at home, and time allocated to complete class assignments. While many of these inequities existed pre-pandemic, many could be mitigated through resources provided in physical classroom environments. Now, more than ever, educators must gauge the extent that these factors are interfering with their learners' abilities to engage in online learning activities and strategize instructional solutions that are contextually responsive.

Nacu et al.'s (2018) ORSL framework and heuristics to evaluate the effectiveness of their identified learner support roles can assist educators with determining if their learning management system, instructional activities, and instructor presence are conducive for learning as they shift to digital environments. Table 1 provides suggestions for how

Table 1 Considerations to address instructional inequities

Online learner support role Strategies to address instructional inequities

Audience

Design opportunities to track learner progress in the online learning space

Provide formative feedback ongoing to remediate learners experiencing challenges with the instructional content

Provide accommodations to activities if you observe a student experiencing challenges beyond their control

Encourager

Evaluator

Friend

Instructor

Learning broker

Model

Monitor

Promotor

Resource provider

Advocate*
Communicate regularly with your learners on upcoming activities Support students by demonstrating flexibility with assignment guidelines

Be considerate of the number of formal assessments administered to students Consider making low-stakes assignments optional

Encourage students to share a part of their world during synchronous online meetings or asynchronous activities

Recognize that some students may not feel comfortable sharing their screen

Determine if the content is to be taught synchronously or asynchronously Provide supports to assist learners as they complete tasks independently

Design opportunities for students to collaborate or interact with one another synchronously and asynchronously

Recognize that students may be accessing content at different times of the day

Model remote studying behaviors for students in addition to desired instructional outcomes

Provide suggestions for students to create a space for learning

Establish expectations for learner performance in the online environment Communicate these expectations to parents/guardians for minors

Create space communal space online for students to share their work and successes. This is especially important if the class is working entirely asynchronously

Provide instructions to students for how to navigate the online learning environment

Provide instructions to parents and guardians to support learners at home

Be consistent with the format and structure used to communicate with students and their guardians

Advocate for students who do not have access to instructional resources at home

Identify strategies to support students who may not have regular access to the internet

Appeal to administration if additional training is needed to support online learners during the pandemic

*Not included as an original learner support role in Nacu et al.'s (2018) paper 
educators can use Nacu et al.'s (2018) learner support roles to address instructional inequities that may be prevalent during the pandemic.

In addition to the learner support roles identified by the authors, educators should consider an additional support role: advocate (see Table 1). Educators must support their learners inside and outside of the learning environment. They must advocate for their students by communicating with their school and district their needs for resourcing to support their learners. This will be particularly important as educational policy adapts in response to new and existing educational challenges.

\section{Limitations and constraints posed by the pandemic}

While online learning offers many affordances that are conducive to supporting the development of twenty first-century skills such as broadening the reach of classrooms, fostering students' development of technological competencies, and promoting learning experiences indicative of creative practices (Greenhow et al. 2009; Mishra et al. 2012), Nacu et al. (2018) noted that some supporting roles may be carried out in face-to-face environment when the teacher is unable to fulfill a particular role in an online environment. While they may have been easily remediated pre-pandemic, teachers' abilities to circumvent these issues in a face-to-face environment have been halted by COVID-19. The recent pandemic has left no stone left unturned; the disparities in remote learning have shone a bright light on the social inequalities many students are experiencing as school systems have shifted to remote learning and online learning. Examples of these inequalities include technical means (i.e. ability to maintain a strong internet connection), limitations to physical access to the internet, disruption of social support networks, and adjusting to learning in an online environment (Beaunoyer et al. 2020; Guitton 2020; Van Lancker and Parolin 2020).

Mitigation strategies offered by Beaunoyer et al. (2020) acknowledge the infrastructural supports needed to acknowledge inequities surrounding physical access as well as the importance of communication. Nacu et al.'s OLSR network can be further enhanced to support teachers' abilities to advocate for their students by instantiating the challenges and disparities many have and will continue to endure this upcoming school year. As teachers shift to online instruction, another consideration is the exploration of how the heuristic method presented by Nacu et al. (2018) can assist educators with evaluating their use of learner supportive roles to address inequities in today's classroom.

Nacu et al.'s paper explicitly stated that their focus was centered on online learning environments that are production-oriented. While teachers must identify opportunities in which their learners can create meaningful artifacts that demonstrate their understanding of instructional material and its application, a limitation is the lack of discussion focused on the process of cultivating these types of production-oriented environments. To date, several scholars have stated that research on pedagogical reasoning and instructional design practices related to learning environments needs to encompass process just as much as the product (Henriksen et al. 2016; Kopcha et al. 2020; McCulloch et al. 2018; Tondeur et al. 2017). Nacu et al.'s (2018) heuristics are somewhat confined to the capabilities of the learning management system; teachers will be more apt to integrate Nacu et al.'s heuristics to support youth learners if they are also provided with strategies on how to integrate these behaviors into their pedagogical reasoning as well as how to generate solutions when working with a learning management system that is not conducive to supporting the learner support roles mentioned in the paper. Teachers will benefit greatly from 
professional development that equips them with developing contextually responsive strategies to accommodate and support their students who may be unintentionally marginalized due to shifts in instructional delivery.

\section{Considerations for the future}

Amidst this pandemic, the education field is standing on the precipice of change for online learning. There is an inherent need to update educational policies to be indicative of today's reality. Deficiencies in our educational systems must be examined at multiple levels (national policies, school districts, and classrooms) to mitigate inadequacies related to teacher professional development, instructional resourcing, and social inequities in our local educational communities as the delivery of instruction is strained during the 2020/2021 academic school year.

Research is needed to identify support mechanisms that address the needs of students and educators in online learning environments in addition to the exploration of the affordances and constraints impacting teachers' pedagogical reasoning while teaching in online learning environments during a pandemic. Furthermore, frameworks are needed to support teacher professional development to be contextually responsive and adaptive while promoting academic rigor.

Reeves and Lin (2020) have appealed to the field of learning, design, and technology to conduct educational design research to address "serious problems related to teaching, learning, and performance" (p. 1). Researchers and educators must come together to advance theory and practice related to online learning in the twenty-first century. The affordances proffered by the learning environment, the instructor, and the learner can help educators identify specific learner support roles needed to address the instructional inequities imposed on their learners.

\section{Compliance with ethical standards}

Conflict of interest The authors declare that they have no conflict of interest.

Informed consent Informed consent was not obtained for this paper and there was no data collection involving human subjects.

\section{References}

Beaunoyer, E., Dupéré, S., \& Guitton, M. J. (2020). COVID-19 and digital inequalities: Reciprocal impacts and mitigation strategies. Computers in Human Behavior, 111, 106424.

Greenhow, C., Robelia, B., \& Hughes, J. E. (2009). Learning, teaching, and scholarship in a digital age: Web 2.0 and classroom research: What path should we take now? Educational Researcher, 38(4), 246-259.

Guitton, M. J. (2020). Cyberpsychology research and COVID-19. Computers in Human Behavior, 111, 106357.

Henriksen, D., Mishra, P., \& Fisser, P. (2016). Infusing creativity and technology in 21 st century education: A systemic view for change. Educational Technology \& Society, 19(3), 27-37.

Kopcha, T. J., Neumann, K. L., Ottenbreit-Leftwich, A., \& Pitman, E. (2020). Process over product: The next evolution of our quest for technology integration. Educational Technology Research and Development, 68(2), 729-749. 
McCulloch, A. W., Hollebrands, K., Lee, H., Harrison, T., \& Mutlu, A. (2018). Factors that influence secondary mathematics teachers' integration of technology in mathematics lessons. Computers \& Education, 123, 26-40.

Mishra, P., Henriksen, D., \& Deep-Play Research Group. (2012). Rethinking technology \& creativity in the 21st century: On being in-disciplined. TechTrends, 56(6), 18-21.

Nacu, D. C., Martin, C. K., Pinkard, N., \& Gray, T. (2016). Analyzing educators' online interactions: A framework of online learning support roles. Learning, Media and Technology, 41(2), 283-305.

Nacu, D., Martin, C. K., \& Pinkard, N. (2018). Designing for 21st century learning online: A heuristic method to enable educator learning support roles. Educational Technology Research and Development, 66(4), 1029-1049.

Reeves, T. C., \& Lin, L. (2020). The research we have is not the research we need. Educational Technology Research and Development, 68, 1991-2001.

Tondeur, J., Van Braak, J., Ertmer, P. A., \& Ottenbreit-Leftwich, A. (2017). Understanding the relationship between teachers' pedagogical beliefs and technology use in education: A systematic review of qualitative evidence. Educational Technology Research and Development, 65(3), 555-575.

Van Lancker, W., \& Parolin, Z. (2020). COVID-19, school closures, and child poverty: A social crisis in the making. The Lancet Public Health, 5(5), e243-e244.

Publisher's Note Springer Nature remains neutral with regard to jurisdictional claims in published maps and institutional affiliations.

Jill Stefaniak is an assistant professor in the Learning, Design, and Technology program at the University of Georgia. Her research focuses on the professional development of instructional designers, designer decisionmaking processes, and contextual factors influencing design in real-world environments. 